\title{
A patentometric analysis of the International Nuclear Information System database: 1970-2006
}

\section{T. Swarna*, Anjali Prabhu, Geeta Nabar, V.L. Kalyane and Vijai Kumar}

Scientific Information Resource Division

Knowledge Management Group

Bhabha Atomic Research Centre

Trombay, Mumbai 400 085, India

E-mail: tswarna@barc.gov.in

E-mail: anjali@barc.gov.in

E-mail: vlk@barc.gov.in

E-mail: vijai@barc.gov.in

*Corresponding author

\begin{abstract}
Of the 46461 patents studied for the period 1970-2006 from the INIS Database, inputs (in percentages) were from Japan (27.9), the USA (23), Germany (13.7), France (11.3) and the UK (7.2). The main languages used were English (35.7), Japanese (27.9), German (14) and French (11.4), out of 20 languages. Patents with percentages in a single category were Engineering and Technology (62.4); Chemistry, Materials and Earth Sciences (13.9); Isotopes and Isotope and Radiation Applications (6.2); Physics (5.5); Life and Environmental Sciences (4.6); Other Aspects of Nuclear and Non-nuclear Energy (0.2); and multidisciplinary (7.2). Among the top inventors, Makoto Ueda had 140 patents, J. Schoening 121 and F.S. Jabsen 115.
\end{abstract}

Keywords: patents; records of patents; database of patents; International Nuclear Information System; INIS.

Reference to this paper should be made as follows: Swarna, T., Prabhu, A., Nabar, G., Kalyane, V.L. and Vijai Kumar (2009) 'A patentometric analysis of the International Nuclear Information System database: 1970-2006', Int. J. Nuclear Knowledge Management, Vol. 3, No. 3, pp.221-235.

Biographical notes: T. Swarna is a Scientific Officer C at the Scientific Information Resource Division, Knowledge Management Group, the Bhabha Atomic Research Centre (BARC), India. She joined BARC in 1989.

Anjali Prabhu is a Scientific Assistant D at the Scientific Information Resource Division, Knowledge Management Group, BARC, India. She joined BARC in 1997.

Geeta Nabar is a Scientific Officer $\mathrm{C}$ at the Scientific Information Resource Division, Knowledge Management Group, BARC, India. She joined BARC in 1991.

V.L. Kalyane is a Scientific Officer F at the Scientific Information Resource Division, Knowledge Management Group, BARC, India. He joined BARC in 1993. 
Vijai Kumar is an Outstanding Scientist, Associate Director of the Knowledge Management Group and Head of the Scientific Information Resource Division, BARC, India. He joined BARC in 1967.

\section{Introduction}

Patents are the largest single source of technological information on inventions of products and methods. Just as scientific articles are accepted as a legitimate reflection of scientific research, patents are accepted as a reflection of technological achievements. The analyses of patents provide an overall view of international technical activity and the technological policies and strategies adopted by nations (Rozhkov and Ivantcheva, 1998).

There are several databases devoted to the coverage of patents literature, such as the International Patent Documentation System (INPADOC), which gives access to national and international patent offices and the World Patent Index (WPI), which provides information on patents from 30 countries. There are also subject-oriented nonpatent databases that include patents besides other types of literature in a particular field, such as the International Nuclear Information System (INIS), Information Service in Physics, Electrotechnology and Control (INSPEC) and the Chemical Abstracts Service (CAS). These and other databases have been used for scientometric studies (Stefaniak, 1987; Oppenheim and Sutherland, 1978). In the present study, the patents retrieved from the INIS database from 1970 to 2006 have been analysed.

\section{About the International Nuclear Information System (INIS)}

INIS, operated by the International Atomic Energy Agency (IAEA), is an international cooperative information system that provides comprehensive bibliographic details of the literature on the peaceful applications of nuclear science and technology. INIS was established in 1970 with a total of 25 members (including countries and international organisations) and in 2006, INIS' membership grew to 140 (IAEA, 2006). The subject scope of INIS consists of nuclear reactors, reactor safety, nuclear fusion, the applications of radiation and radioisotopes in medicine, agriculture, industry and pest control and the related fields include nuclear chemistry, nuclear physics and materials science. The literature covered by the INIS database includes journal articles, reports, conference papers, books, patents, theses, laws, regulations and standards. This database is distributed free of charge to the participating member states and organisations. In 2006, the INIS database included 2.7 million bibliographic references. This database is accessible by subscription only and had in 2006 about 1.3 million authorised users.

Some of the previous studies done using the INIS database include the following: Bonitz (1985) described a method of ranking journals according to a new parameter (Selective Impact) and applied it to study journals publishing papers on nuclear research using the INIS database. Huxlin (2002) has studied Australia's share of publications in the INIS database in the subfields of nuclear chemistry, physics, materials science and nuclear medicine. Barrett (1970) has compared CAS, INSPEC, the Medical 
Literature Analysis and Retrieval System (MEDLARS) and INIS, which revealed considerable international activity at working levels towards establishing global scientific and technical information systems. Marinkovic (2002) has conducted a bibliometric study of research reactors in the INIS database for the period from 1970 to 2001 . Hillebrand $(1998 \mathrm{a}-\mathrm{c})$, in three separate studies, has analysed publications on fusion research and technology in the INIS database during 1970 to mid-1998, literature on high-energy physics in the same period and literature on low and medium-energy physics. Negeri (2005) has analysed records on the Chernobyl accident and its consequences covered by the INIS database from 1986 to 2005. Kademani et al. (2006) have analysed India's contribution to the INIS database during 1970 to 2002.

\section{Objectives of the study}

The specific objectives of the present paper were to study the publication trends of the patents in nuclear science and technology included in the INIS database for the following characteristics:

- proportion of patents compared to other types of literature

- year-wise analysis of patents

- country-wise input

- language-wise distribution

- time-lag index

- pioneer first inventors and patronising first inventors

- content analysis.

\section{Materials and methods}

Database on CD-ROM, brought out by INIS during 1970 to 2006, was used for the study. A search was made for 'patent' in the field 'type of document', which resulted in 46461 patents being retrieved from the database. Bibliographic fields such as the publication year of the patent, country of input, language, volume number of the database, authors and subject codes were downloaded for each record.

\section{Results and discussion}

\subsection{Proportion of patents compared to other types of literature}

Table 1 indicates the year-wise proportion of patents compared to other types of literature in the INIS database from 1970-2006. 
224 T. Swarna, A. Prabhu, G. Nabar, V.L. Kalyane and Vijai Kumar

Table 1 The year-wise proportion of patents in the INIS database from 1970-2006

\begin{tabular}{|c|c|c|c|c|}
\hline \multicolumn{2}{|c|}{ INIS database } & \multirow{2}{*}{$\begin{array}{l}\text { Total number } \\
\text { of documents }\end{array}$} & \multirow{2}{*}{$\begin{array}{l}\text { Number of } \\
\text { patents }\end{array}$} & \multirow{2}{*}{$\begin{array}{l}\text { Percentage } \\
\text { of patents }\end{array}$} \\
\hline Volume no. & Year & & & \\
\hline 1 & 1970 & 3981 & 0 & 0.00 \\
\hline 2 & 1971 & 10408 & 0 & 0.00 \\
\hline 3 & 1972 & 20846 & 202 & 0.97 \\
\hline 4 & 1973 & 56614 & 924 & 1.63 \\
\hline 5 & 1974 & 63614 & 1772 & 2.78 \\
\hline 6 & 1975 & 63296 & 1746 & 2.76 \\
\hline 7 & 1976 & 60478 & 2469 & 4.08 \\
\hline 8 & 1977 & 69028 & 2516 & 3.64 \\
\hline 9 & 1978 & 70795 & 2279 & 3.22 \\
\hline 10 & 1979 & 75966 & 2828 & 3.72 \\
\hline 11 & 1980 & 76599 & 2242 & 2.93 \\
\hline 12 & 1981 & 70820 & 2022 & 2.86 \\
\hline 13 & 1982 & 72718 & 2256 & 3.10 \\
\hline 14 & 1983 & 92216 & 2019 & 2.19 \\
\hline 15 & 1984 & 73362 & 1503 & 2.05 \\
\hline 16 & 1985 & 86529 & 2154 & 2.49 \\
\hline 17 & 1986 & 90401 & 2887 & 3.19 \\
\hline 18 & 1987 & 101118 & 2378 & 2.35 \\
\hline 19 & 1988 & 106919 & 1889 & 1.77 \\
\hline 20 & 1989 & 86281 & 1590 & 1.84 \\
\hline 21 & 1990 & 95604 & 1547 & 1.62 \\
\hline 22 & 1991 & 92012 & 1249 & 1.36 \\
\hline 23 & 1992 & 88990 & 1587 & 1.78 \\
\hline 24 & 1993 & 76577 & 1325 & 1.73 \\
\hline 25 & 1994 & 77107 & 1228 & 1.59 \\
\hline 26 & 1995 & 79021 & 743 & 0.94 \\
\hline 27 & 1996 & 80854 & 906 & 1.12 \\
\hline 28 & 1997 & 80899 & 936 & 1.16 \\
\hline 29 & 1998 & 67994 & 726 & 1.07 \\
\hline 30 & 1999 & 61398 & 385 & 0.63 \\
\hline 31 & 2000 & 65768 & 111 & 0.17 \\
\hline 32 & 2001 & 69662 & 2 & 0.00 \\
\hline 33 & 2002 & 71306 & 0 & 0.00 \\
\hline 34 & 2003 & 84574 & 13 & 0.01 \\
\hline 35 & 2004 & 107062 & 20 & 0.02 \\
\hline 36 & 2005 & 117230 & 6 & 0.00 \\
\hline 37 & 2006 & 122498 & 1 & 0.00 \\
\hline Total & & 2790545 & 46461 & 1.66 \\
\hline
\end{tabular}


The initial two years, 1970 and 1971, did not include any patents in the database. Subsequently, the percentage of patents included compared to other types of literature increased gradually and was at a maximum of $4.08 \%$ (2469) in 1976. The maximum number of patents added to the database in a year was 2887 in 1986 and then declined gradually to no patents being included in the database in 2002, 13 in 2003, 20 patents in 2004, 6 in 2005 and 1 in 2006. The overall proportion of patents in the database was $1.66 \%$ compared to other types of literature. This skewed distribution of patents in the database may be on two accounts: the patent laws prevailing in the participating nations and/or the laxity on the part of the participating nations and organisations.

Figure 1 indicates the quinquennial publication trend of a number of patents and their cumulation in the INIS database (1970-2006). A maximum number of patents (11 887) were added in the second quinquennium (1977-1981) and then there was a steep fall in the number of added patents. Approximately 50\% (22 706) of the patents included in the database were in the second and third quinquennium (1977-1986) and 75\% (31 359) from 1977-1991. From then on, there has been a steady decrease in the number of patents added to the database.

Figure 1 The quinquennial publication trend of the number of patents published and their cumulation in the INIS database (1970-2006)

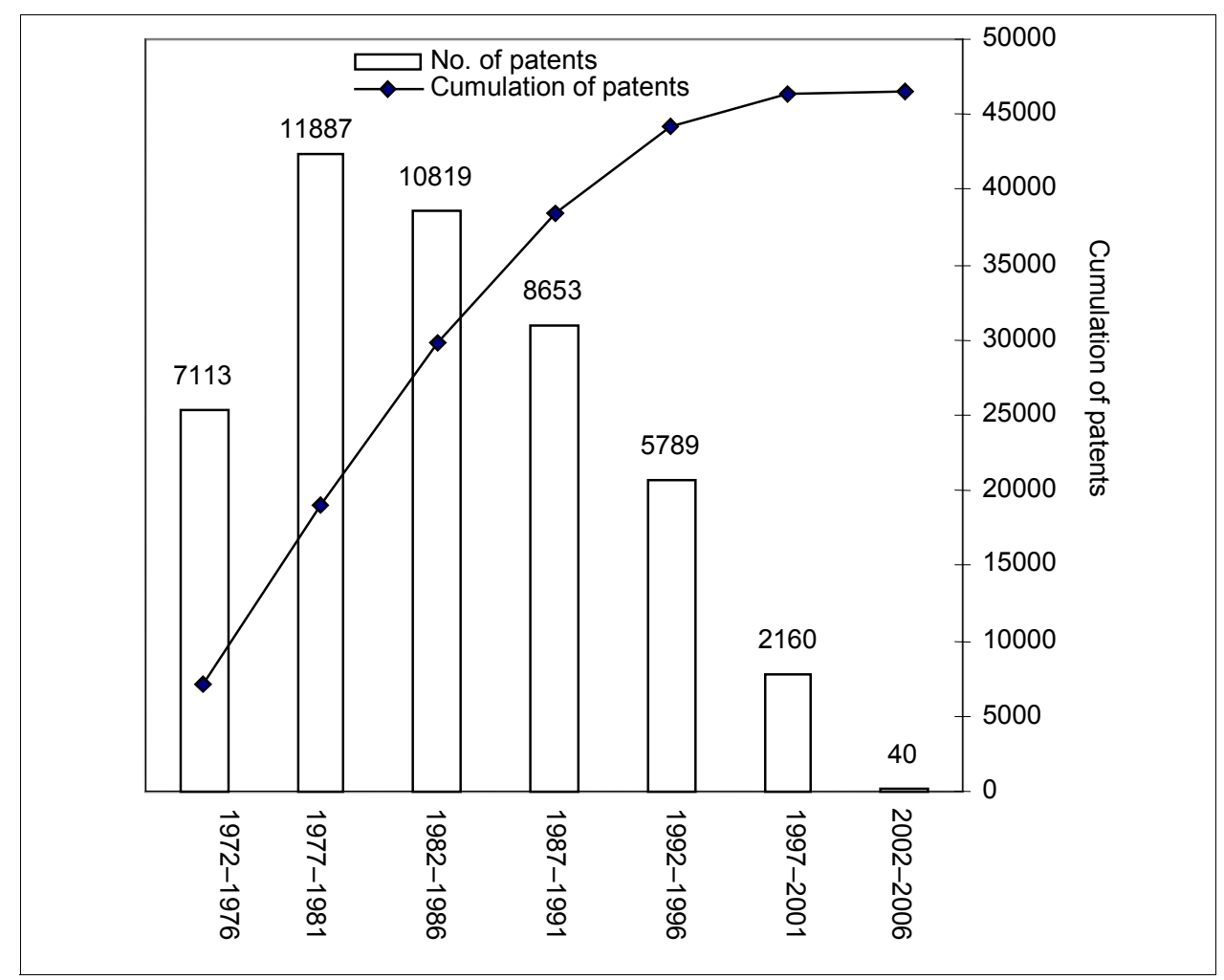




\subsection{Year-wise analyses of patents}

Figure 2a gives the year-wise distribution of the patents in the INIS database from 1970 to 2006 .

The inclusion of patents in the INIS database was very gradual, with only one patent in 1951 and 1952 being included in the database and no patents of 1953 to 1961 (Figure 2b). The maximum numbers of patents included in the database was in 1975 (2749) and 1976 (2712). Two patents were excluded in this segment of the study because their year of publication was not known.

Figure 2a The patents in the INIS database from 1970-2006 compared to other types of literature

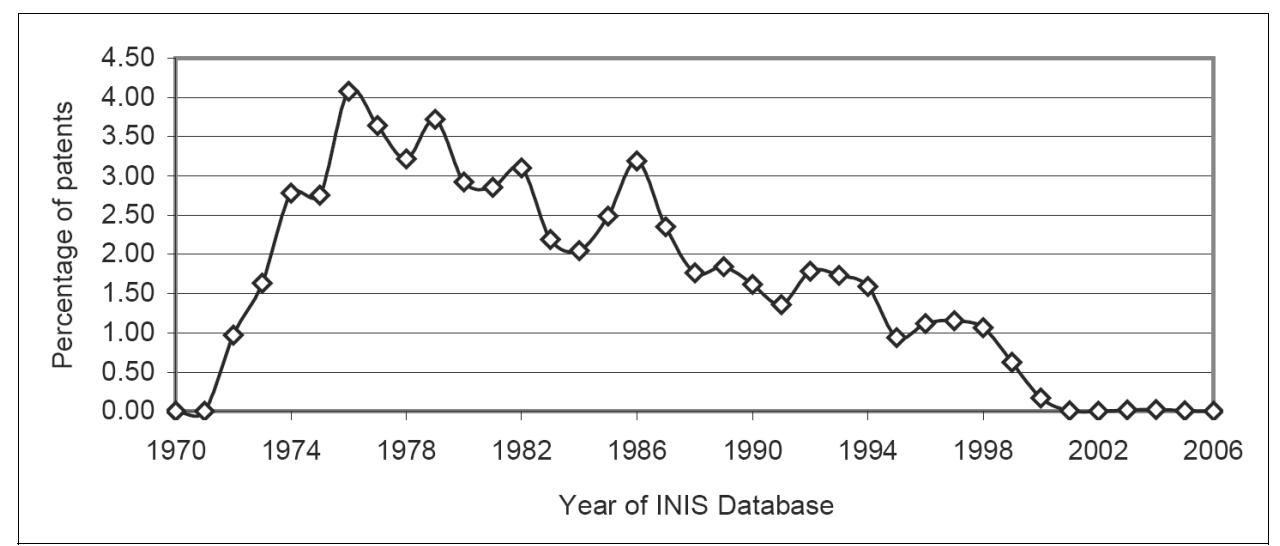

Figure 2b The year-wise number of patents published in the INIS database (1970-2006)

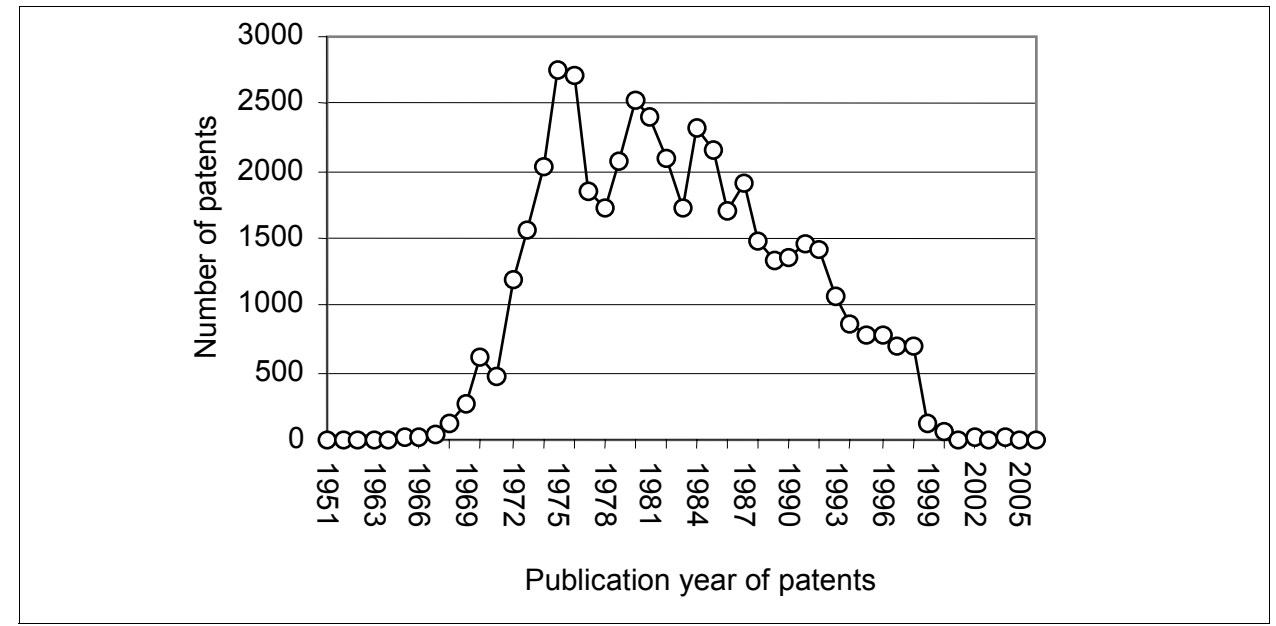

\subsection{Country-wise input analyses of patents}

Each bibliographic record in the INIS database is assigned with the country of input as one of its attributes. Though this does not mean that the country of input is the same as the country of the contributing author/s, it is still indicative of the country's contribution to the database. 
A total of 46461 patents were contributed by 34 countries and one organisation - the Commission of the European Communities (Table 2).

Table 2 The country-wise input of patents in the INIS database (1970-2006)

\begin{tabular}{|c|c|c|}
\hline Country of input & No. of patents & Percentage \\
\hline Japan & 12953 & 27.9 \\
\hline USA & 10668 & 23.0 \\
\hline Germany & 6360 & 13.7 \\
\hline France & 5272 & 11.3 \\
\hline UK & 3331 & 7.2 \\
\hline USSR & 1644 & 3.5 \\
\hline Czechoslovakia & 1548 & 3.3 \\
\hline Canada & 1253 & 2.7 \\
\hline The Netherlands & 939 & 2.0 \\
\hline Australia & 784 & 1.7 \\
\hline South Africa & 452 & 1.0 \\
\hline Sweden & 228 & 0.5 \\
\hline Switzerland & 160 & 0.3 \\
\hline Norway & 159 & 0.3 \\
\hline Bulgaria & 129 & 0.3 \\
\hline Austria & 122 & 0.3 \\
\hline Poland & 78 & 0.2 \\
\hline Denmark & 65 & 0.1 \\
\hline Hungary & 62 & 0.1 \\
\hline Czech Republic & 64 & 0.1 \\
\hline Russian Federation & 41 & 0.1 \\
\hline Republic of Moldova & 62 & 0.1 \\
\hline Commission of the European Communities & 33 & 0.1 \\
\hline Belgium & 24 & 0.1 \\
\hline Kazakhstan & 9 & 0.0 \\
\hline Mongolia & 5 & 0.0 \\
\hline Brazil & 5 & 0.0 \\
\hline Romania & 3 & 0.0 \\
\hline Finland & 3 & 0.0 \\
\hline Italy & 2 & 0.0 \\
\hline Lithuania & 1 & 0.0 \\
\hline Sri Lanka & 1 & 0.0 \\
\hline Algeria & 1 & 0.0 \\
\hline Total & 46461 & 100.0 \\
\hline
\end{tabular}


The top five countries contributing almost $75 \%$ (38 582) of the patents to the INIS database are: Japan (27.9\%), the USA (23.0\%), Germany (13.7\%), France (11.4\%) and the UK $(7.2 \%)$.

The year-wise contributions of the five most productive nations (Japan, the USA, Germany, France and the UK) are indicated in Table 3. Two French patents whose publication years were not known have been excluded from Table 3 and Figure 3.

The contributions of all these nations have drastically declined in the recent years, with no contributions from the UK since 1996, Germany since 1997, France since 1998, Japan since 2000 and the USA since 2001. Hillebrand (1998c), in his study of publications related to fusion research and technology in the INIS database (1970 to mid-1998), has noted that the input of patents had been erratic during this period probably due to the change in the patent law in some countries and the difficulty of converting records from patent to bibliographic database. However, there was an increase of patents input during this period probably due to the increased effort to commercialise research and technological results. Figure 3 indicates the cumulation of patents of the top five contributing countries.

\subsection{Language-wise analyses of patents}

A total of 46461 patents were published in 20 languages (Table 4). Of these, 16606 (35.7\%) were in English, 12953 (27.9\%) were in Japanese, 6527 (14.1\%) were in German and 5317 (11.4\%) were in French.

\subsection{Time-lag index}

The time lag between the publication and its appearance in indexing and abstracting services is of paramount importance both to users and librarians who are concerned with current references in a particular field. The currency of literature published in secondary sources is also one of the factors considered for the evaluation of the source (Jacso, 1998). Few studies have been conducted on the time lag of indexing and abstracting services (Smalley, 1980; Corth, 1977; Poyer, 1982; Miller and Rau, 1977; Robinson and Turtle, 1974; Williams, 1972; Braun et al., 2001).

The patents were analysed for time lag between the publication year of the patent and the year of its incorporation in the INIS database. The time lag was taken as zero if the publication year of the patent and the year in which it was included in the database was the same. Two French patents whose publication years were not known have been excluded from this segment of the study.

Figure 4 depicts a similar trend for $50 \%$ and $100 \%$ of the patents included in the INIS database. The time taken for $50 \%$ of the yearly patents to appear in the database is known as ' 50 percentile' and the time taken for $100 \%$ of the patents to appear in the database is called ' 100 percentile'.

There is a definite indication that the participating nations are making efforts to keep the database as current as possible. 
Table 3 The year-wise number of patents input by the top five countries in the INIS database (1970-2006)

\begin{tabular}{|c|c|c|c|c|c|}
\hline Year of publication of patent & Japan & $U S A$ & Germany & France & $U K$ \\
\hline 1962 & 3 & & & & \\
\hline 1963 & 1 & & & & \\
\hline 1964 & 6 & 1 & & & \\
\hline 1965 & 13 & & & & \\
\hline 1966 & 10 & & & & \\
\hline 1967 & 35 & 2 & & & \\
\hline 1968 & 105 & 1 & & 12 & \\
\hline 1969 & 223 & 6 & 3 & 15 & \\
\hline 1970 & 343 & 18 & 9 & 215 & \\
\hline 1971 & 37 & 48 & 13 & 285 & \\
\hline 1972 & 16 & 102 & 133 & 341 & 163 \\
\hline 1973 & 16 & 445 & 127 & 381 & 197 \\
\hline 1974 & 58 & 698 & 234 & 359 & 98 \\
\hline 1975 & 535 & 693 & 530 & 374 & 102 \\
\hline 1976 & 496 & 654 & 699 & 308 & 111 \\
\hline 1977 & 33 & 364 & 794 & 248 & 105 \\
\hline 1978 & 177 & 347 & 626 & 126 & 100 \\
\hline 1979 & 524 & 241 & 588 & 78 & 266 \\
\hline 1980 & 491 & 480 & 453 & 208 & 408 \\
\hline 1981 & 488 & 547 & 200 & 183 & 414 \\
\hline 1982 & 497 & 387 & 250 & 147 & 217 \\
\hline 1983 & 480 & 336 & 275 & 129 & 128 \\
\hline 1984 & 487 & 801 & 345 & 149 & 137 \\
\hline 1985 & 524 & 606 & 440 & 165 & 188 \\
\hline 1986 & 500 & 350 & 320 & 180 & 121 \\
\hline 1987 & 500 & 637 & 267 & 179 & 119 \\
\hline 1988 & 500 & 413 & 50 & 126 & 91 \\
\hline 1989 & 508 & 378 & 0 & 165 & 75 \\
\hline 1990 & 608 & 356 & 3 & 131 & 79 \\
\hline 1991 & 634 & 526 & 1 & 111 & 59 \\
\hline 1992 & 597 & 518 & & 141 & 67 \\
\hline 1993 & 589 & 218 & & 150 & 37 \\
\hline 1994 & 559 & 84 & & 139 & 47 \\
\hline 1995 & 561 & 24 & & 151 & 2 \\
\hline 1996 & 600 & 73 & & 74 & \\
\hline 1997 & 586 & 80 & & & \\
\hline 1998 & 606 & 86 & & & \\
\hline 1999 & 7 & 107 & & & \\
\hline 2000 & & 38 & & & \\
\hline \multicolumn{6}{|l|}{2001} \\
\hline \multicolumn{6}{|l|}{2002} \\
\hline \multicolumn{6}{|l|}{2003} \\
\hline 2004 & & 1 & & & \\
\hline 2005 & & 2 & & & \\
\hline Total & 12953 & 10668 & 6360 & 5270 & 3331 \\
\hline
\end{tabular}


Figure 3 The cumulation of patents input by top five countries as per the INIS database (1970-2006)

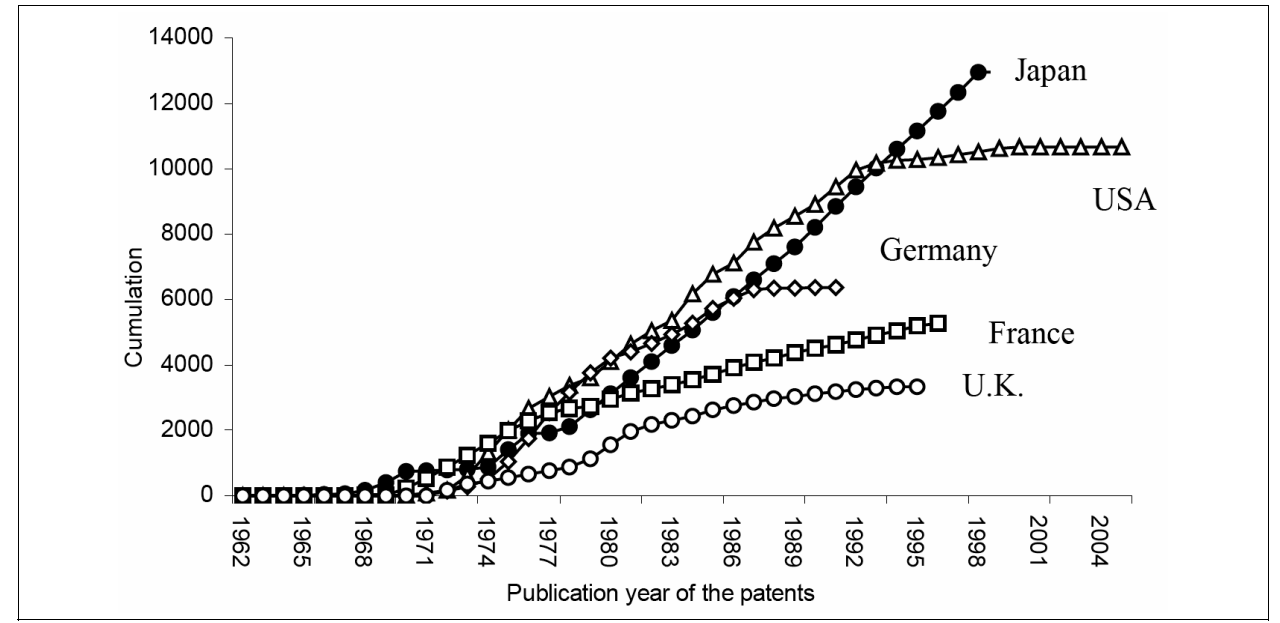

Table 4 The language-wise distribution of patents in the INIS database (1970-2006)

\begin{tabular}{lrc}
\hline Language & No. of patents & Percentage \\
\hline English & 16609 & 35.75 \\
Japanese & 12953 & 27.88 \\
German & 6527 & 14.05 \\
French & 5317 & 11.44 \\
Russian & 1708 & 3.67 \\
Czech & 1445 & 3.11 \\
Dutch & 947 & 2.04 \\
Swedish & 228 & 0.49 \\
Norwegian & 158 & 0.34 \\
Slovak & 156 & 0.34 \\
Bulgarian & 129 & 0.28 \\
Polish & 78 & 0.17 \\
Danish & 65 & 0.14 \\
Romanian & 65 & 0.14 \\
Hungarian & 62 & 0.13 \\
Portuguese & 5 & 0.01 \\
Mongolian & 3 & 0.01 \\
Finnish & 3 & 0.01 \\
Italian & 2 & 0.0 \\
Lithuanian & 1 & 0.0 \\
Total & 461 & 100.0 \\
\hline
\end{tabular}


Figure 4 The trend of time lag (in years) of patents for $50 \%$ and $100 \%$ of the patents included in the INIS database (1970-2006)

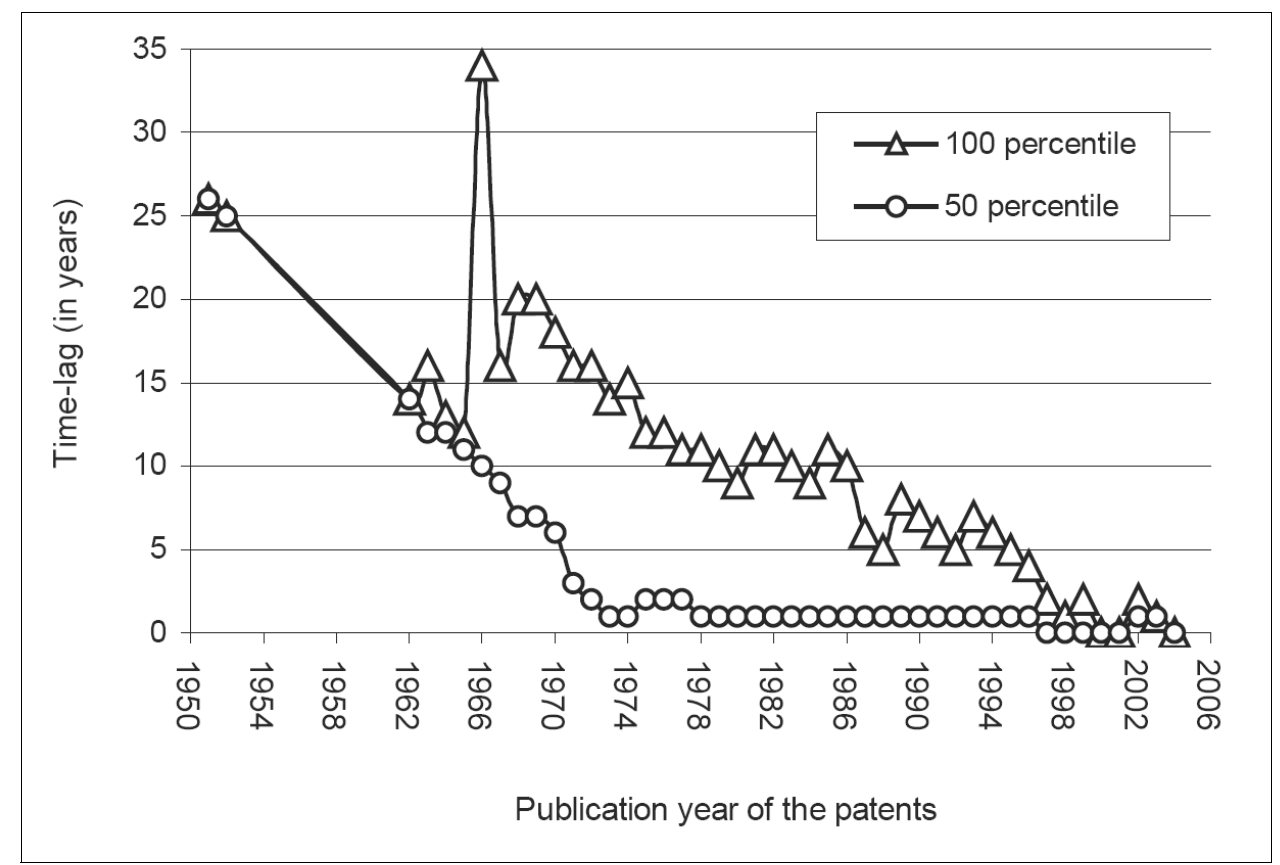

\subsection{Pioneer first inventors and patronising first inventors}

Patent productivity is highly concentrated in a relatively small number of talented individuals. There were 95588 inventors (authorships) who produced 46461 patents. The number of inventors ranged from 1 to 20 for each patent. The inventors may either be first inventors or co-inventors. The first inventors are considered the scientific mentors. They may be classified as 'patronising first inventors', i.e., those who contribute less as first inventor and more as co-inventor or they may be 'pioneer first inventors', i.e., those who contribute more as first inventor and less as co-inventor (Gupta, 2004).

Table 5 indicates the contribution analysis of the top 20 inventors, of whom 16 are pioneer first inventors and four, patronising first inventors.

\subsection{Content analysis}

The INIS' subject classification scheme was used for the content analysis. Since the inception of the INIS in 1970, its subject categories and scope descriptions (in conformity with the International Classification System for Physics developed by the International Council for Scientific and Technical Information) were used. In January 2000, these subject categories have been replaced by the new INIS and Energy Technology Data Exchange (ETDE) subject categorisation scheme (International Atomic Energy Agency, 2002). Since the new categories are very broad, those patents classified by the new scheme were converted into the old classification scheme and included in the study. 
Table 5 The contribution analysis of the top 20 inventors in the INIS database (1970-2006)

\begin{tabular}{|c|c|c|c|c|}
\hline Inventor & $\begin{array}{l}\text { As first } \\
\text { inventor }\end{array}$ & $\begin{array}{l}\text { As sole } \\
\text { inventor }\end{array}$ & As co-inventor & $\begin{array}{c}\text { Total } \\
\text { patents }\end{array}$ \\
\hline Ueda, Makoto (pioneer) & 46 & 65 & 29 & 140 \\
\hline Schoening, J. (patronising) & 33 & 2 & 86 & 121 \\
\hline Jabsen, F.S. (pioneer) & 18 & 97 & 0 & 115 \\
\hline Schabert, H.P. (pioneer) & 50 & 20 & 28 & 98 \\
\hline Matal, O. (pioneer) & 53 & 6 & 30 & 89 \\
\hline Arnold, D.M. (patronising) & 29 & 18 & 35 & 82 \\
\hline Sykora, D. (pioneer) & 27 & 40 & 1 & 68 \\
\hline Elter, C. (pioneer) & 44 & 0 & 23 & 67 \\
\hline Yoshioka, Ritsuo (patronising) & 5 & 24 & 28 & 57 \\
\hline Nakatsuka, Masafumi (patronising) & 9 & 35 & 11 & 55 \\
\hline Hida, Kazuki (pioneer) & 17 & 21 & 17 & 55 \\
\hline Givens, W.W. (pioneer) & 13 & 35 & 4 & 52 \\
\hline Hounsfield, G.N. (pioneer) & 8 & 39 & 2 & 49 \\
\hline Shirakawa, Toshihisa (pioneer) & 9 & 35 & 5 & 49 \\
\hline Bevilacqua, F. (pioneer) & 16 & 28 & 2 & 46 \\
\hline Anthony, A.J. (pioneer) & 17 & 26 & 3 & 46 \\
\hline Kimura, Tadashi (pioneer) & 31 & 0 & 13 & 44 \\
\hline Baatz, H. (pioneer) & 30 & 4 & 0 & 34 \\
\hline Shallenberger, J.M. (pioneer) & 27 & 1 & 5 & 33 \\
\hline Stiefel, M. (pioneer) & 8 & 21 & 0 & 29 \\
\hline Total & & & & 1329 \\
\hline
\end{tabular}

All the subject categories of the patents were downloaded for analysis. The patents were given up to three subject categories by INIS. The patents with one subject category accounted for $92.8 \%$ (43 135 patents), $7 \%$ (3223 patents) was with two subject categories and $0.2 \%$ (103 patents) was with three subject categories.

Engineering and Technology (Category E) accounted for $62.4 \%$ of the patents and Chemistry, Materials and Earth Sciences (Category B), 13.9\% (Table 6). Table 7 depicts the interdisciplinarity of the patents with two subject categories. The highest number of patents of an interdisciplinary nature was 930 of Category B: Chemistry, Materials and Earth Sciences and Category E: Engineering and Technology, 658 were of Category C: Life and Environmental Sciences and Category E: Engineering and Technology. 
Table 6 The subject classification of patents in the INIS database (1970-2006)

\begin{tabular}{lcc}
\hline INIS subject category & No. of patents & Percentage \\
\hline E: Engineering and Technology & 29000 & 62.4 \\
B: Chemistry, Materials and Earth Sciences & 6443 & 13.9 \\
D: Isotopes and Isotope and Radiation Applications & 2894 & 6.2 \\
G: Physics & 2532 & 5.5 \\
C: Life and Environmental Sciences & 2158 & 4.6 \\
F: Other aspects of nuclear and non-nuclear energy & 108 & 0.2 \\
Multisubjects & 3326 & 7.2 \\
Total & 46461 & 100 \\
\hline
\end{tabular}

Table 7 The disciplinary and interdisciplinary contents of patents in INIS database (1970-2006)

\begin{tabular}{lccccrrr}
\hline$*$ & $B$ & $C$ & $D$ & $E$ & $F$ & \multicolumn{1}{c}{$G$} & Total \\
\hline B & 6443 & 272 & 423 & 930 & 9 & 251 & 8328 \\
C & & 2158 & 103 & 658 & 7 & 7 & 2933 \\
D & & 2894 & 239 & 1 & 74 & 3208 \\
E & & & 29000 & 66 & 181 & 29247 \\
F & & & & 108 & 2 & 110 \\
G & & & & & & 2532 & 2532 \\
Total & 6443 & 2430 & 3420 & 30827 & 191 & 3047 & 46358 \\
\hline
\end{tabular}

Note: $\quad$ * INIS subject categories in the first column and the row is as per Table 6 .

\section{Conclusion}

The proportion of patents in the INIS database from 1970 to 2006 was only $1.66 \%$ (46 461). The patents were contributions of 34 countries and one organisation - the Commission of the European Communities. The major contributions were by Japan $(27.9 \%)$, the USA $(23 \%)$, Germany $(13.7 \%)$, France $(11.3 \%)$ and the UK $(7.2 \%)$. The contributions of these five countries steadily declined, with no patents being contributed by Japan since 2000, the USA since 2001 (only one and two patents added in 2004 and 2005, respectively), Germany since 1992, France since 1997 and the UK since 1996. The 46461 patents were published in 20 languages, of which $35.7 \%$ were in English, $27.9 \%$ were in Japanese, $14.1 \%$ were in German and $11.4 \%$ were in French. The time-lag index of patents appearing in the INIS database improved considerably over 37 years. The number of inventors of these 46461 patents were 95 588, of which Makoto Ueda ranked first by contributing 140 patents, J. Schoening ranked second (121 patents) and F.S. Jabsen ranked third (115 patents).

Of the 20 inventors, 16 were 'pioneer first inventors' (those who contribute more as first inventor and less as co-inventor) and 4 were 'patronising first inventors' (those who contribute less as first inventor and more as co-inventor). The subject-wise distribution of the 46461 patents indicated that $43135(92.8 \%)$ of the patents were with a single 
subject, of which 29000 were on the Engineering and Technology category. Of the multidisciplinary patents, 3223 were of two subject categories and 103 patents were of three subject categories.

Though bibliographic databases are powerful tools for scientometric studies, one has to be aware of certain limitations (such as the coverage of a subject field) as far as world literature is concerned, the span of time for retrospective searches, time lag appearing in the database, lack of complete bibliographic details in all records and variations and inconsistencies in the records. The coverage of literature in a given database compared to the world literature in a particular field may be limited due to various reasons. Even in databases covering world literature, publications of the country of the producer and countries of the same region or language often show better coverage than others. Some countries give better coverage to certain types of literature than others. INIS does not suffer from such a bias because it is created by its member states and organisations that follow definite rules and regulations that are jointly decided by them. Its coverage and quality, therefore, depends on the efforts of the participating states and organisations.

One should also bear in mind the serious limitations to the use of patent data, the most glaring being the laws and policies governing the countries from time to time.

\section{References}

Barrett, J.W. (1970) 'Subject and mission-oriented schemes: the international pattern as indicated by CAS, INSPEC, INIS and others', Aslib Proceedings, Vol. 22, No. 8, pp.386-394.

Bonitz, M. (1985) 'Journal ranking by selective impact, new method based on SDI results and journal impact factors', Scientometrics, Vol. 7, Nos. 3-6, pp.471-485.

Braun, T., Diospatonyi, T. and Horvai, G. (2001) 'A study of publication time of chemical databases’, Tudomanyos-es-Muszaki-Tajekoztatas, Vol. 49, Nos. 9-10, pp.375-382.

Corth, A. (1977) 'Coverage of marine biology citations', Special Libraries, Vol. 68, No. 12, pp.439-446.

Gupta, V.K. (2004) 'Inventors' productivity in a publicly funded R\&D agency - the case of CSIR in India', World Patent Information, Vol. 26, No. 3, pp.235-238.

Hillebrand, C.D. (1998a) 'Analysis of high energy physics records in databases: science and technology indicators in high energy physics', http://www.iaea.org/inis/ws/articles/ hillebrand0399.pdf.

Hillebrand, C.D. (1998b) 'Low and medium energy physics records', NDS Collection, IAEA, Vienna, http://www-nds.ieae.org/reports-new/ndc-reports/indc-nds/indc-nds-0391.pdf.

Hillebrand, C.D. (1998c) 'Survey of publications in fusion research and technology: science and technology indications in fusion R\&T', ITER-Newsletter, IAEA, Vienna, Austria, 4-6 April, http://www.iaea.org/inis/ws/articles/hillebrand1098.pdf.

Huxlin, M. (2002) 'International Nuclear Information System (INIS) at ANSTO', France-Australia Symposium on Nuclear Medicine, 29 April, p.61.

IAEA (2006) 'Annual report', pp.22-23.

International Atomic Energy Agency (2002) 'Subject categories and scope descriptions', ETDE/ INIS Joint Reference Series No. 2.

Jacso, P. (1998) 'Content evaluation of databases', in M.E. Williams (Ed.) (1997) Annual Review of Information Science and Technology, American Society for Information Science, Medford, NJ: Information Today, Inc., Vol. 32, pp.231-267.

Kademani, B.S., Kumar, V., Sagar, A. and Kumar, A. (2006) 'Scientometric dimensions of nuclear science and technology research in India: a study based on INIS (1970-2002) Database', Malaysian Journal of Library \& Information Science, Vol. 11, No. 1, pp.23-48. 
Marinkovic, N. (2002) 'Research reactor records in the INIS database: a bibliometric study', http://www.iaea.org/inis/ws/articles/research_reactors.pdf.

Miller, B. and Rau, S.L. (1977) 'Investigation of the index lag of Engineering Index and Electrical and Electronics Abstracts', Part II in B.M. Fry (Ed.) Information Management in the 1980s: Proceedings of the 40th ASIS Annual Meeting, White Plains, New York, American Society for Information Science, Chicago, Illinois, 26 September-1 October, Vol. 14.

Negeri, B. (2005) 'Knowledge resources on the Chernobyl accident and its consequences in the INIS database: a bibliometric study', http://www.iaea.org/iniskm/nkm/ws/articles/chernobyl/ 2005.pdf.

Oppenheim, C. and Sutherland, E.A. (1978) 'Studies on the metallurgical patent literature 1: the coverage of patents by abstracts journals in metallurgy', Journal of Chemical Information and Computer Sciences, Vol. 18, No. 3, pp.122-126.

Poyer, R.K. (1982) 'Time lag in four indexing services', Special Libraries, Vol. 73, No. 2, pp.142-146.

Robinson, W.C. and Turtle, M.R. (1974) 'The relationship between time lag and place of publication in library and information science abstracts and library literature', $R Q$, Vol. 14, No. 1 , pp.28-31.

Rozhkov, S. and Ivantcheva, L. (1998) 'Scientometrical indicators of national science \& technology policy based on patent statistics data', World Patent Information, September-December, Vol. 20, Nos. 3-4, pp.161-166.

Smalley, T.N. (1980) 'Comparing psychological abstracts and Index Medicus for coverage of the journal literature in a subject area in psychology', Journal of the American Society for Information Science, Vol. 31, No. 3, pp.143-146.

Stefaniak, B. (1987) 'Use of bibliographic data bases for scientometric studies', Scientometrics, Vol. 12, Nos. 3-4, pp.149-161.

Williams, M.E. (1972) 'Time lapse between the appearance of citations in Chemical Titles and Chemical Abstracts', Journal of Chemical Documentation, Vol. 12, No. 4, p.217. 